\title{
Adolescent and Adult Children of Parents with Parkinson's Disease: Incorporating Their Needs in Clinical Guidelines
}

\author{
David Morley, ${ }^{1}$ Caroline Selai, ${ }^{1}$ Anette Schrag, ${ }^{2}$ Marjan Jahanshahi, ${ }^{1}$ and Alan Thompson ${ }^{1}$ \\ ${ }^{1}$ Institute of Neurology, University College London, Queen Square, London WC1N 3BG, UK \\ ${ }^{2}$ UCL Medical School, University College London, London NW3 2PF, UK \\ Correspondence should be addressed to David Morley, d.morley@open.ac.uk
}

Received 20 January 2011; Accepted 25 April 2011

Academic Editor: Francisco Grandas

Copyright ( 2011 David Morley et al. This is an open access article distributed under the Creative Commons Attribution License, which permits unrestricted use, distribution, and reproduction in any medium, provided the original work is properly cited.

\begin{abstract}
Purpose. To compare the quality of life (QoL) and emotional well-being of the offspring of parents with Parkinson's disease (PD) and multiple sclerosis (MS) and to consider results in light of current UK clinical guidelines. Methods. 143 adolescent and adult children of parents with PD and MS were postally administered the Parental Illness Impact Scale and a measure of emotional wellbeing. Results. Minimal differences were observed between the two groups in both QoL and emotional well-being. Levels of mild to moderate depression were substantially greater than those of the general population. Conclusions. The nonsignificant differences reported indicate a similar degree of impact across the two conditions assessed. A significant body of evidence demonstrates the considerable impact of parental MS, with the needs of children being acknowledged in current clinical guidelines. There is a need to similarly acknowledge the potential impact of parental Parkinson's in UK guidelines for PD.
\end{abstract}

\section{Introduction}

The impact of neurological illness on the well-being of children of affected individuals has, until recently, remained largely underinvestigated. An exception to this is multiple sclerosis (MS) where a body of research has developed, particularly over the last 10 years [1-7]. Recently, however, studies have been published on the impact of a broader range of parental neurological conditions, including Parkinson's disease (PD) and stroke [8-12], although investigation of the former in particular remains limited. To the best of our knowledge, to date just two studies have focused specifically on the impact of parental PD $[8,9]$.

Studies which focus on children's response to parental illness and disability identify a number of recurrent themes. Children report elevated levels of depression and anxiety $[1,11-14]$, with changing roles and heightened responsibility $[2,9,15,16]$. This in turn can have negative implications for their independence [9]. The provision of information for children regarding their parent's condition is also frequently raised $[7,9,16,17]$. Previous studies also indicate that not all parental conditions affect children similarly. For example, some have suggested that children of parents with spinal cord injury appear well adjusted to their parent's condition $[18,19]$, and that children of people with multiple sclerosis (PWMS) can adjust well to their parent's condition [20]. Additionally, children of parents with inflammatory bowel disease report some positive as well as negative responses to their parent's condition [17].

The importance of continued investigation of children's response to parental neurological illness is underscored by the current disparity in recognition of the impact of some parental conditions in relevant clinical guidelines. An example of this is the current UK guidelines for PD and MS $[21,22]$. The former currently makes no reference to the children of affected individuals. The lack of previous research and the perception that $\mathrm{PD}$ is a condition where children will always be "grown-up", are likely to be contributing factors in this. This is in stark contrast to UK guidelines for the clinical management of MS which incorporate recommendations relating to the potential impact on affected individuals children based on the body of research evidence relating to parental MS.

The aims of this paper are therefore twofold: first to make an assessment of the quality of life (QoL) and emotional well-being of adolescent and adult offspring of 
people with Parkinson's (PWP), and PWMS, in order to test the hypothesis that that there will be significant differences between these two groups. The second aim is to consider the results in the context of current clinical guidelines for the management of PD and MS.

\section{Methods}

2.1. Participants. Adolescent (ages11-17) and adult offspring were recruited through a number of routes. Offspring of PWP who had participated previously in the studies of Schrag et al. $[9,23]$ were invited to take part. The study was also advertised in The Parkinson, the quarterly publication of the UK Parkinson's Disease Society, YAPMAG, the quarterly publication of Young Alert Parkinson's, and Partners and Relatives (YAPP\&Rs, now the Younger Parkinson's Network), a support group dedicated to young-onset PD patients and their families. Offspring of PWMS was recruited via the support charities, the Scottish MS Society, and the MS Trust.

2.2. Materials. Questionnaires were administered to assess the QoL and emotional well-being of participants. Instruments for adolescent and adult offspring differed to account for developmental stage as outlined below.

Participants aged between 11 and 17 were asked to complete the following questionnaires: (i) Parental Illness Impact Scale-Revised (PIIS-R) [24], a 51-item instrument designed specifically to assess the impact of parental illness, and constructed around a QoL model. The PIIS-R is comprised of 37 items over 8 subscales scored on a 5-point Likert scale, with higher scores indicating superior QoL. The maximum score is 185 , and the instrument has been shown to possess both sound reliability $(\alpha=.92)$ and validity [24]. The PIIS-R also incorporates 14 dichotomous items focusing on the needs of children regarding provision of information and sources of support. (ii) Birleson Depression Self Rating Scale (DSRS) [25]. The DSRS includes eighteen items, each having the three response choices of "Most of the Time", "Sometimes" and "Never". The maximum score is 36. A score of 13 and above is regarded as indicating depressed mood, with higher scores indicative of increased levels of depression. The instrument is regarded as a reliable and valid tool in the assessment of adolescent depression, demonstrating high internal consistency $(\alpha=.90)[26,27]$.

Participants aged 18 and above were administered the following: (i) PIIS-R, as described previously. (ii) Beck Depression Inventory (BDI) [28], a widely used 21-item inventory assessing the somatic, affective, and behavioural symptoms of depression. Response options are $0-3$, leading to a maximum possible score of 63. Cut-off scores generally employed are 0-9 indicating no depression, 1017 mild depression, 18-24 moderate depression, and 25 and above indicating severe depression. A review of studies incorporating the BDI has shown it to display sound internal consistency ( $\alpha=.73-.92)$ in nonpsychiatric samples [29].

Ethical approval for the study was provided by the Joint Research Ethics Committee of the National Hospital for Neurology and Neurosurgery and the Institute of Neurology,
TABle 1: Sample characteristics.

\begin{tabular}{lcc}
\hline Parental Condition & PD & MS \\
\hline Sample size & 81 & 62 \\
Adolescent : Adult & $16: 65$ & $24: 38$ \\
Mean age & $27.22(9.80)$ & $21.37(8.18)$ \\
Male : Female & $32: 49$ & $28: 34$ \\
$\begin{array}{l}\text { Mean duration of parent's } \\
\text { condition in years }\end{array}$ & $10.56(6.15)$ & $11.65(7.62)$
\end{tabular}

(Standard deviation).

Queen Square, London. Consent was obtained from parents of children under the age of 18. Questionnaires were mailed to participants, with follow-up letters mailed to nonrespondents four weeks later. A response rate of $76 \%$ was achieved.

2.3. Statistical Analysis. Data were checked for presence of outliers and normality of distribution prior to statistical analysis. Dependent on distribution and sample size, Mann Whitney and independent samples t-tests were calculated to assess differences between groups. Percentage values were calculated to assess levels of depression and the practical needs of participants as indicated by dichotomous variables of the PIIS-R.

\section{Results}

The total sample consisted of 143 adolescent and young adult participants. As might be expected due to the average age of onset of the two parental conditions, there was a significant difference in age between the two samples $(t=$ $3.78, P<.00)$, with offspring of PWP older than offspring of PWMS. There was, however, no significant difference in parental disease duration $(t=1.00, P>$.05). Further sociodemographic data according to parental condition are presented in Table 1.

Mean adjusted values for QoL and self-reported levels of depression by parental condition are presented in Table 2 .

3.1. Assessment of QoL. Significant differences between the two groups are reported in just one subscale of the PIISR. Children of PWP report greater concerns for their future than those of PWMS $(t=-2.05, P<.05)$. No significant differences between the two groups are observed in total QoL scores $(t=1.12, P>.05)$. Percentage scores for PIIS-R dichotomous variables providing supplementary information regarding provision of information and sources of support are presented in Table 3.

3.2. Assessment of Emotional Well-Being. No statistically significant differences were observed between the two groups in either adolescent $(z=-0.80, P>.05)$ or adult $(t=-0.84, P>.05)$ self-reported depression. Whilst mean values for both groups fall below the levels regarded indicative of mild to moderate depression, further analysis identified the percentage of participants reporting levels of depression above the relevant cut-off points for the DSRS 
TABLE 2: Mean values by parental condition for QoL and depression.

\begin{tabular}{lcc}
\hline & $\begin{array}{c}\text { Children of } \\
\text { PWP } \\
(n=81)\end{array}$ & $\begin{array}{c}\text { Children of PWMS } \\
(n=62)\end{array}$ \\
\hline $\begin{array}{l}\text { PIIS-R Subscale } \\
\text { Burden of daily help }\end{array}$ & $3.97(0.84)$ & $3.87(0.84)$ \\
$\quad$ Emotional impact & $3.80(0.81)$ & $3.63(0.87)$ \\
Social impact & $4.38(0.68)$ & $4.21(0.78)$ \\
Communication and & $3.56(0.74)$ & $3.39(0.85)$ \\
understanding & $3.35(0.90)$ & $3.68(1.03)$ \\
$\quad$ Impact on personal future & $4.41(0.79)$ & $4.31(0.85)$ \\
Friends reactions & $3.55(0.84)$ & $3.48(0.82)$ \\
$\quad$ Parent/child relationship & $3.31(0.87)$ & $3.04(0.77)$ \\
$\quad$ Global well-being & $30.35(4.18)$ & $29.61(4.39)$ \\
PIIS-R total score & $6.62(4.62)$ & $8.37(6.49)$ \\
Birleson DSRS & $6.20(6.72)$ & $7.27(4.80)$ \\
Beck Depression Inventory & &
\end{tabular}

(Standard deviation).

and BDI. Mild to moderate depression was evident in $17.7 \%$ of children of PWP and $31.1 \%$ of PWMS.

\section{Discussion}

The data presented assesses the response of adolescent and young adults to parental PD and MS in relation to QoL and emotional well-being. The hypothesis that there would be significant differences between the two groups is largely rejected, indicating a similar degree of impact across the two parental conditions assessed. The implications of these results, and particularly their relevance to current UK clinical guidelines for Parkinson's disease, are further discussed below.

Referring specifically to QoL, there is no statistically significant difference in total PIIS-R scores. A significant difference is evident in only one of the eight subscales, Impact on Personal Future, with offspring of PWP reporting greater concerns. This may reflect the uncertain, protracted, and chronic progressive natures of PD. Results from the dichotomous items of the PIIS-R are also largely similar across the two groups. Of particular note is that in both groups approximately $40 \%$ report not having enough information about their parent's condition, with only approximately $45 \%$ indicating that they know enough about what will happen in the future to their parent. These results and previous studies $[7,9,16,17]$ emphasise the need to have appropriate and accessible information available for children of affected parents. Other similar results include over $60 \%$ from both groups indicating that more assistance should be provided by external services. A wide disparity is seen, however, in the actual provision of external assistance in helping to care for the affected parent. Only $41 \%$ of children of parents with Parkinson's report the availability of such help, as opposed to $55 \%$ of children of PWMS. Additionally, over $52 \%$ of children of PWP feel it would help them to have training in giving practical care to their affected parent as opposed to $37 \%$ of PWMS. These results may reflect poor service provision and a lack of recognition of the needs of PWP and the wider family unit. On the more positive side, both children of PWP and PWMS report encouraging results when asked about some aspects relating to communication and support. Over $70 \%$ from both groups report having somebody to talk to about the parental condition, support from family and friends, and ways to cope with any feelings of anger. It may well be that the smaller numbers from both groups (21-35\%) who feel it would be helpful to have either personal or family counselling are those not experiencing such positive communication and support.

Assessment of emotional well-being again shows no significant differences between the two groups assessed. In both groups, however, levels of mild to moderate depression are greater than those of current population estimates: $17.7 \%$ of children of PWP and $31.1 \%$ of PWMS. Prevalence of depression in adults in the general population is estimated at $5 \%-10 \%[30]$ and in adolescents at $4 \%-8 \%[31,32]$. The UK government has recognised the importance of mental health in primary care in their national service framework [33] and also specifically in children and adolescents [34]. This is further highlighted in guidelines published by the National Institute for Health and Clinical Excellence (NICE) for the treatment of depression in children and adolescents [35]. As has been reported in other studies, the key to the effective treatment of depression remains its recognition and treatment in both adolescents and adults [36, 37]. The NICE guidelines reiterate this in recommending that "healthcare professionals in primary care, schools, and other relevant community settings should be trained to detect symptoms of depression and to assess children who may be at risk of depression." It is therefore important that children confronted with parental illness, be they young or adult, are recognised as being at increased risk of mental health problems, as is supported by the levels of self-reported depression in this and other studies $[1,4]$.

The similar degree of impact reported across both conditions has important implications. A number of studies have shown the considerable effects of parental MS [1-7], and the current study suggests the need to acknowledge the potentially negative impact of having a parent with PD and possibly a wider range of conditions. Such an acknowledgement is made in the UK government's National Service Framework for Long-Term Conditions [38]. One of the 11 "quality requirements" (QR) focuses on the support of carers and family members of affected individuals and notes the deleterious effect parental neurological conditions can have on children, and the need to ensure that children do not fall into the role of carers. The $\mathrm{QR}$ goes on to emphasise the adjustments families may need to make in light of behavioural and cognitive changes in the patient and that assistance might be required in doing so, with a "whole family approach," including children, being recommended. The document also provides "evidence-based markers of good practice," and amongst these is the recommendation that services provide support for children of patients. However, in assessing individual clinical guidelines for the 
TABle 3: Percentage values by parental condition for dichotomous variables of PIIS-R.

\begin{tabular}{|c|c|c|}
\hline PIIS-R item & $\mathrm{PD} \%$ & MS\% \\
\hline (43) Have enough information & 62.5 & 57.1 \\
\hline (44) Know enough about what will happen in the future to parent & 46.3 & 43.5 \\
\hline (45) Rely solely on parents for information about parent's condition & 61.3 & 68.3 \\
\hline (46) Have somebody to talk to about parent's illness if want to & 70.4 & 69.8 \\
\hline (47) Have support from friends and family & 81.3 & 77.0 \\
\hline (48) Have ways to cope with any feelings of anger & 74.5 & 72.5 \\
\hline (49) Parent talks about their condition & 77.5 & 66.7 \\
\hline (50) Would help to have contact with people in similar circumstances & 43.6 & 29.0 \\
\hline (51) Would help to have training in giving practical care & 52.5 & 37.1 \\
\hline (52) Would help to have opportunity for counselling & 35.0 & 31.7 \\
\hline (53) Would help to have counselling as family & 21.5 & 22.2 \\
\hline (54) Outside help available to help care for affected parent & 40.8 & 55.0 \\
\hline (55) Think more help (e.g., meals on wheels, physiotherapy) should be provided by services & 61.0 & 61.9 \\
\hline (56) Would help to be able to talk to local services about help provided to parent & 40.5 & 28.6 \\
\hline
\end{tabular}

parental conditions reported in this study, there is wide disparity in recognising the needs of children.

\subsection{Clinical Guidelines}

4.1.1. Parkinson's Disease. The NICE guidelines for Parkinson's disease [21] were published in 2006, with an expected review date of 2011. The document makes no reference to the children of PWP. Early in these guidelines, there is a focus on "communication with people with Parkinson's disease and their carers." The section is introduced by highlighting that "good communication is at the heart of every interaction between people with PD, their carers, and health professionals". Results reported in this paper underline that this communication must also extend to the children of those with PD, be they young or adult. Nearly $40 \%$ of participants reported not having enough information about their parent's PD, and over 50\% reported similarly in the study of Schrag et al. (2004) [9].

4.1.2. Multiple Sclerosis. In stark contrast to the guidelines for PD, the NICE guidelines for multiple sclerosis [22] do recognise the significant emotional and practical needs of children of PWMS. The document makes clear from the outset that general principles should incorporate support for family and carers. Specifically the document states:

"Family members (including any schoolchildren) living in the same house as the person with MS, and any family members delivering substantial support even if living elsewhere, should be supported by:

(i) Asking about their physical and emotional health and well-being, especially in the case of children aged 16 years or less, and offering advice and referring on for additional support if necessary

(ii) Providing them with general factual information about $M S$; this should only be extended to include more specific information related to the person with MS with the permission of that person (iii) Ensuring that they are willing to undertake support of personal activities of daily living (such as dressing and toileting), are safe and competent at such tasks, and that the person with MS is happy for them to provide such assistance

(iv) Informing them about social services carer assessment and support procedures."

Other areas related specifically to children that are considered include the extent to which the PWMS is able to care for their children, based on their ability to perform activities of daily living. Considerable emphasis is placed on appropriate training of family members who assist the PWMS. Such a focus on the emotional and practical needs of children is not apparent in the clinical guidelines for PD, and from the data presented it is recommended that such an approach needs to be considered. The current differences in guidelines between MS and PD may be explained in part by the perception that MS is a condition which usually affects young adults while PD tends to be associated with a later age of onset. However, this is not always the case and in approximately 5-10\% Parkinson's is apparent prior to age forty [39].

4.2. Limitations of Current Study. In considering the participants, this was a self-selected sample due to the mode of recruitment, and therefore is unlikely to be entirely representative of the target population. It is therefore acknowledged that there may be a degree of bias in the results. Additionally, it is recognised that some parents of participants may have had atypical Parkinsonism, although this was not assessed. Atypical Parkinson's may have a greater effect on the family and there is a need to ensure that such variations in Parkinsonism are taken into consideration in future research. There is also a need to consider whether the parent has a genetic component to their Parkinson's. Approximately 20\% of those diagnosed with early onset Parkinson's are thought to have genetic factors associated with their condition [40] 
and this may well heighten the impact on children and the concerns they have for their future.

With regard to methodology, the relatively small samples sizes incorporated in the study have implications for statistical power. Caution is therefore warranted when interpreting the results. These sample sizes also limit further analysis on the needs of subgroups, such as adolescents compared to adults, as current numbers do not allow for meaningful analysis. Future research might focus on the specific needs of such groups and qualitative research may further enhance such investigation. Caution is also required regarding the comparisons made with studies that estimate levels of depression in the general population. Measures of depression such as those used in this study can produce higher estimates than those which incorporate clinical criteria (i.e., DSM IV or ICD10) or are clinician administered [41]. There are also limitations as to what can be concluded from the results presented in the absence of comparative data from adolescent and adult offspring of healthy parents. Finally, there is a limit to what can be concluded from a cross-sectional design such as that employed in this study. Longitudinal data is required to make a more detailed evaluation of the wellbeing of children of neurologically affected parents over time and particularly with chronic progressive conditions such as PD.

\section{Conclusions}

Results presented serve to highlight the potentially damaging effects of parental Parkinson's on both adolescent and adult children and that their needs must not go unrecognised. There is a need for this to be acknowledged in current UK clinical guidelines, and this should be addressed in future revisions of guidelines relating to Parkinson's disease.

\section{Conflict of Interests}

The authors declare that there is no conflict of interests.

\section{Acknowledgment}

This research was supported by a Ph. D. studentship from the Parkinson's Disease Society, UK.

\section{References}

[1] R. Yahav, J. Vosburgh, and A. Miller, "Separationindividuation processes of adolescent children of parents with multiple sclerosis," Multiple Sclerosis, vol. 13, no. 1, pp. 87-94, 2007.

[2] R. Yahav, J. Vosburgh, and A. Miller, "Emotional responses of children and adolescents to parents with multiple sclerosis," Multiple Sclerosis, vol. 11, no. 4, pp. 464-468, 2005.

[3] K. I. Pakenham and S. Bursnall, "Relations between social support, appraisal and coping and both positive and negative outcomes for children of a parent with multiple sclerosis and comparisons with children of healthy parents," Clinical Rehabilitation, vol. 20, no. 8, pp. 709-723, 2006.

[4] B. Steck, F. Amsler, A. Grether et al., "Mental health problems in children of somatically ill parents, e.g. multiple sclerosis,"
European Child and Adolescent Psychiatry, vol. 16, no. 3, pp. 199-207, 2007.

[5] M. A. De Judicibus and M. P. McCabe, "The impact of parental multiple sclerosis on the adjustment of children and adolescents," Adolescence, vol. 39, no. 155, pp. 551-569, 2004.

[6] B. Steck, F. Amsler, L. Kappos, and D. Bürgin, "Gender-specific differences in the process of coping in families with a parent affected by a chronic somatic disease (e.g. multiple sclerosis)," Psychopathology, vol. 34, no. 5, pp. 236-244, 2001.

[7] T. Cross and D. Rintell, "Children's perceptions of parental multiple sclerosis," Psychology, Health and Medicine, vol. 4, no. 4, pp. 355-360, 1999.

[8] R. Grimshaw, Children of Parents with Parkinson's Disease: A Research Report for the Parkinson's Disease Society, National Children's Bureau, London, UK, 1991.

[9] A. Schrag, D. Morley, N. Quinn, and M. Jahanshahi, "Impact of Parkinson's disease on patients' adolescent and adult children," Parkinsonism and Related Disorders, vol. 10, no. 7, pp. 391-397, 2004.

[10] I. G. L. van de Port, A. M. A. Visser-Meily, M. W. M. Post, and E. Lindeman, "Long-term outcome in children of patients after stroke," Journal of Rehabilitation Medicine, vol. 39, no. 9, pp. 703-707, 2007.

[11] A. Visser-Meily, M. Post, A. M. Meijer, C. Maas, M. Ketelaar, and E. Lindeman, "Children's adjustment to a parent's stroke: determinants of health status and psychological problems, and the role of support from the rehabilitation team," Journal of Rehabilitation Medicine, vol. 37, no. 4, pp. 236-241, 2005.

[12] A. Visser-Meily, M. Post, A. M. Meijer, I. Van De Port, C. Maas, and E. Lindeman, "When a parent has a stroke: clinical course and prediction of mood, behavior problems, and health status of their young children," Stroke, vol. 36, no. 11, pp. 2436-2440, 2005.

[13] D. W. Black, G. R. Gaffney, S. Schlosser, and J. Gabel, "Children of parents with obsessive-compulsive disorder-a 2-year follow-up study," Acta Psychiatrica Scandinavica, vol. 107, no. 4, pp. 305-313, 2003.

[14] R. Forehand, R. Steele, L. Armistead, P. Simon, E. Morse, and L. Clark, "The family health project: psychosocial adjustment of children whose mothers are HIV infected," Journal of Consulting and Clinical Psychology, vol. 66, no. 3, pp. 513-520, 1998.

[15] L. Strunin and L. I. Boden, "Family consequences of chronic back pain," Social Science and Medicine, vol. 58, no. 7, pp. 1385-1393, 2004.

[16] C. L. M. Caton, F. Cournos, A. Felix, and R. J. Wyatt, "Childhood experiences and current adjustment of offspring of indegent patients with schizophrenia," Psychiatric Services, vol. 49, no. 1, pp. 86-90, 1998.

[17] S. Mukherjee, P. Sloper, and R. Lewin, "The meaning of parental illness to children: the case of inflammatory bowel disease," Child: Care, Health and Development, vol. 28, no. 6, pp. 479-485, 2002.

[18] F. M. Buck and G. W. Hohmann, "Personality, behavior, values, and family relations of children of fathers with spinal cord injury," Archives of Physical Medicine and Rehabilitation, vol. 62, no. 9, pp. 432-438, 1981.

[19] C. J. Alexander, K. Hwang, and M. L. Sipski, "Mothers with spinal cord injuries: impact on marital, family, and children's adjustment," Archives of Physical Medicine and Rehabilitation, vol. 83, no. 1, pp. 24-30, 2002.

[20] K. A. Blackford, "Strategies for intervention and research with children or adolescents who have a parent with multiple sclerosis," Axone, vol. 14, no. 2, pp. 50-54, 1992. 
[21] National Institute for Health \& Clinical Excellence, Parkinson's Disease: National Clinical Guideline for Diagnosis and Management in Primary and Secondary Care, HMSO, London, UK, 2006.

[22] National Institute for Health \& Clinical Excellence, Multiple Sclerosis: National Clinical Guideline for Diagnosis and Management in Primary and Secondary Care, HMSO, London, UK, 2004.

[23] A. Schrag, D. Morley, N. Quinn, and M. Jahanshahi, "Development of a measure of the impact of chronic parental illness on adolescent and adult children. The Parental Illness Impact Scale (Parkinson's disease)," Parkinsonism and Related Disorders, vol. 10, no. 7, pp. 399-405, 2004.

[24] D. Morley, C. Selai, A. Schrag, A. J. Thompson, and M. Jahanshahi, "Refinement and validation of the Parental Illness Impact Scale," Parkinsonism and Related Disorders, vol. 16, no. 3, pp. 181-185, 2010.

[25] P. Birleson, "The validity of depressive disorder in childhood and the development of a self-rating scale: a research report," Journal of Child Psychology and Psychiatry and Allied Disciplines, vol. 22, no. 1, pp. 73-88, 1981.

[26] T. Ivarsson, A. Lidberg, and C. Gillberg, "The Birleson Depression Self-Rating Scale (DSRS). Clinical evaluation in an adolescent inpatient population," Journal of Affective Disorders, vol. 32, no. 2, pp. 115-125, 1994.

[27] T. Ivarsson and C. Gillberg, "Depressive symptoms in Swedish adolescents: normative data using the Birleson Depression Self-Rating Scale (DSRS)," Journal of Affective Disorders, vol. 42, no. 1, pp. 59-68, 1997.

[28] A. T. Beck, C. H. Ward, M. Mendelson, J. Mock, and J. Erbaugh, "An inventory for measuring depression," Archives of General Psychiatry, vol. 4, pp. 561-571, 1961.

[29] A. T. Beck, R. A. Steer, and M. G. Garbin, "Psychometric properties of the Beck Depression Inventory: twenty-five years of evaluation," Clinical Psychology Review, vol. 8, no. 1, pp. 77100, 1988.

[30] N. Singleton, R. Bumpstead, M. O'Brien, A. Lee, and H. Meltzer, "Psychiatric morbidity among adults living in private households, 2000," International Review of Psychiatry, vol. 15, no. 1-2, pp. 65-73, 2003.

[31] P. Hazell, "Depression in children and adolescents," Clinical Evidence, no. 8, pp. 330-339, 2009.

[32] S. E. Son and J. T. Kirchner, "Depression in children and adolescents," American Family Physician, vol. 62, no. 10, pp. 2297-2308, 2000.

[33] Department of Health. The National Service Framework for Mental Health, Modern Standards and Service Models, HMSO, London, UK, 1999.

[34] H. Meltzer, R. Gatward, R. Goodman, and T. Ford, "Mental health of children and adolescents in Great Britain," International Review of Psychiatry, vol. 15, no. 1-2, pp. 185-187, 2003.

[35] National Institute for Health \& Clinical Excellence, Depression in Children and Young People: Identification in Primary, Community and Secondary Care, HMSO, London, UK, 2005.

[36] L. Rowe, B. Tonge, and G. Melvin, "When should GPs prescribe SSRIs for adolescent depression?" Australian Family Physician, vol. 33, no. 12, pp. 1005-1008, 2004.

[37] D. Kessler, K. Llyod, G. Lewis, and D. P. Gray, "Cross sectional study of symptom attribution and recognition of depression and anxiety in primary care," British Medical Journal, vol. 318, no. 7181 , pp. 436-440, 1999.
[38] Department of Health, National Service Framework for LongTerm Conditions, Department of Health, London, UK, 2005.

[39] C. E. Clarke and A. P. Moore, "Parkinson's disease," American Family Physician, vol. 75, no. 7, pp. 1045-1048, 2007.

[40] C. Klein, "Implications of genetics on the diagnosis and care of patients with Parkinson disease," Archives of Neurology, vol. 63, no. 3, pp. 328-334, 2006.

[41] T. S. Brugha, P. E. Bebbington, R. Jenkins et al., "Cross validation of a general population survey diagnostic interview: a comparison of CIS-R with SCAN ICD-10 diagnostic categories," Psychological Medicine, vol. 29, no. 5, pp. 1029-1042, 1999. 


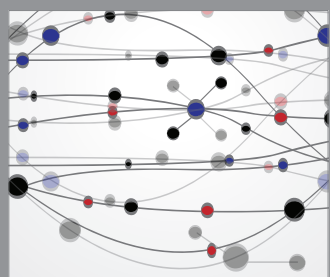

The Scientific World Journal
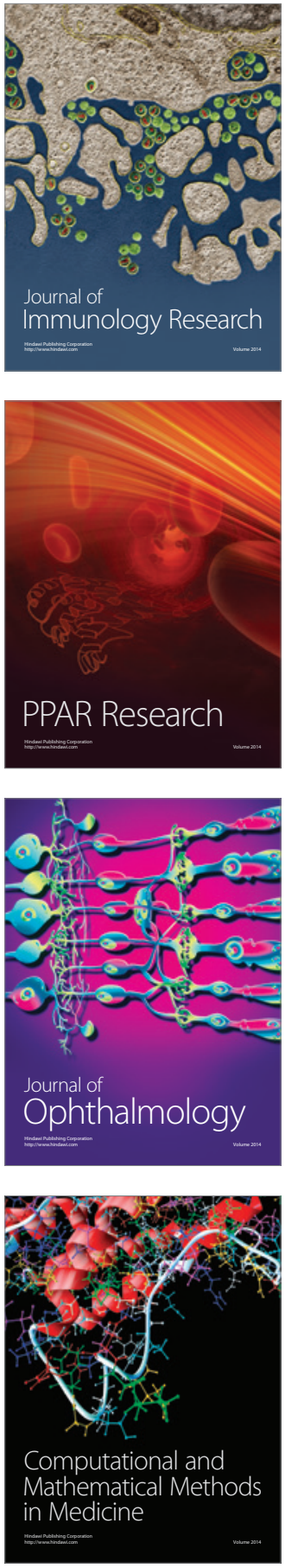

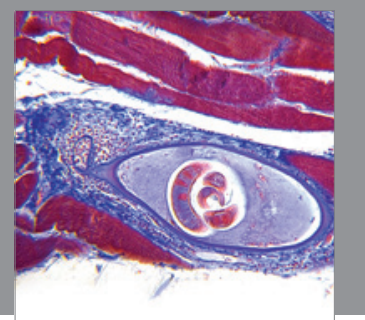

Gastroenterology

Research and Practice
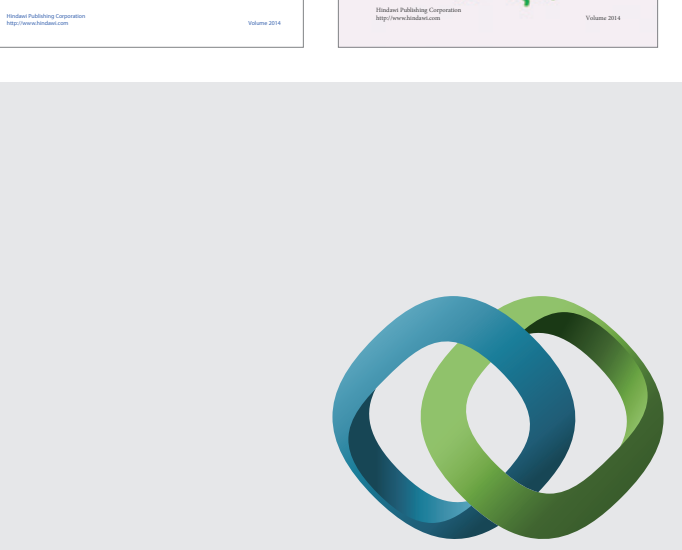

\section{Hindawi}

Submit your manuscripts at

http://www.hindawi.com
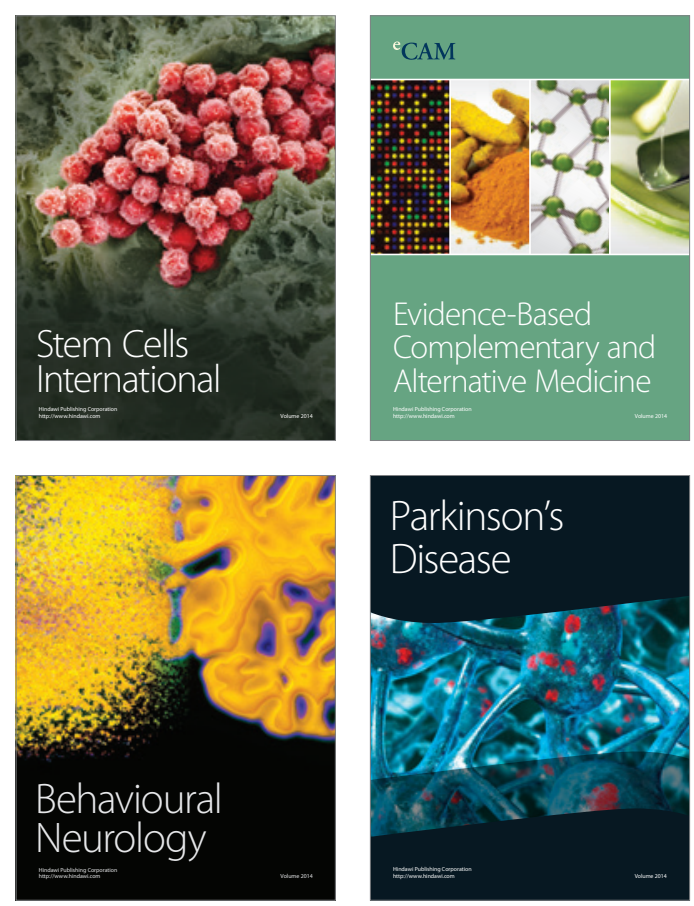

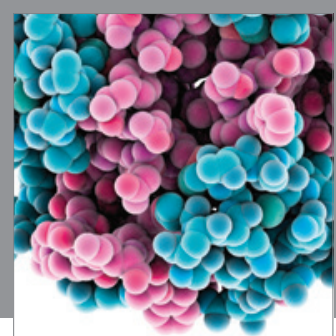

Journal of
Diabetes Research

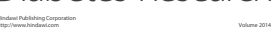

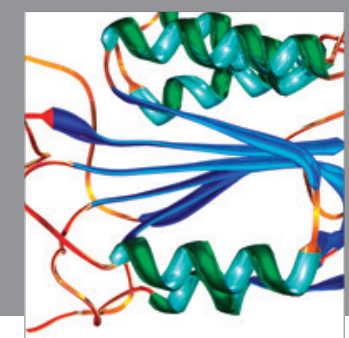

Disease Markers
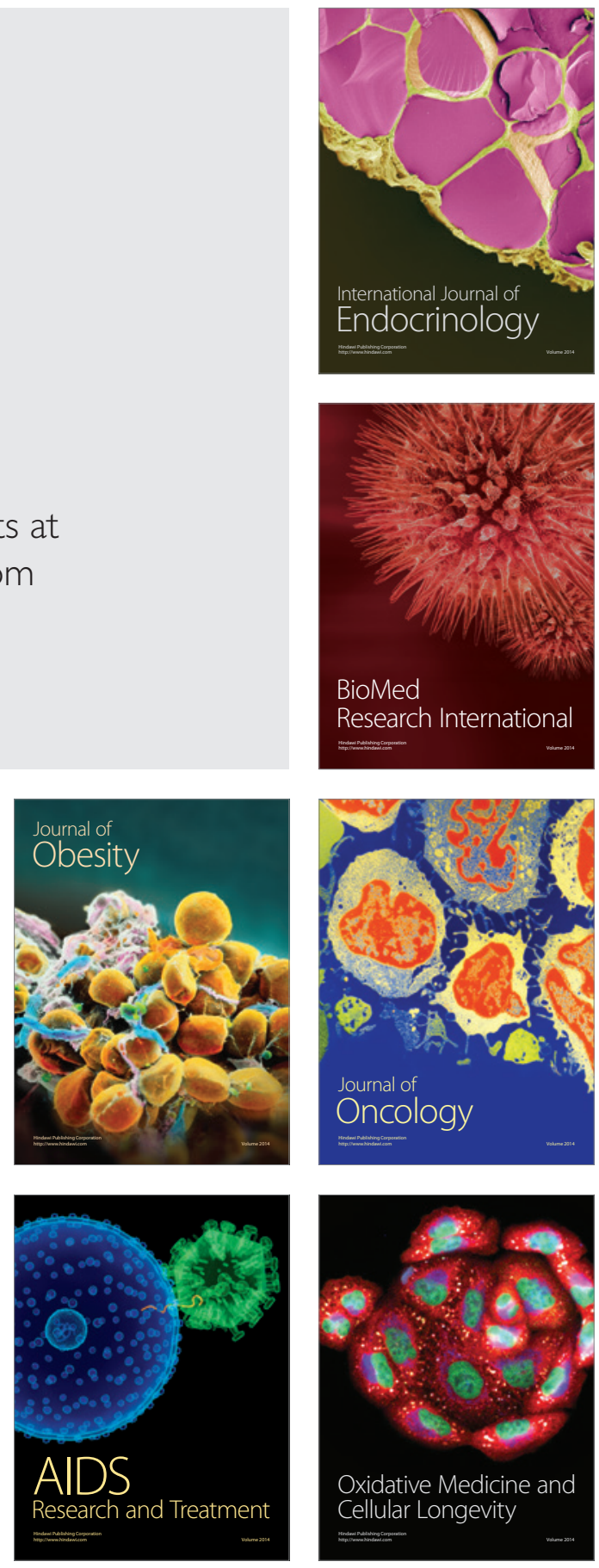